\title{
Anthropogenic lead isotopes in Antarctica
}

\author{
K.J.R. Rosman and W. Chisholm \\ Department of Applied Physics, Curtin University of Technology, Bentley, Australia \\ C.F. Boutron ${ }^{1}$ and J.-P. Candelone \\ Laboratoire de Glaciologie et Géophysique de l'Environnement du CNRS., St Martin d'Hères, France
}

\section{C.C. Patterson}

Califormia Institute of Technology, Pasadena

\begin{abstract}
We report the first measurements of $\mathrm{Pb}$ isotopes in Antarctic snow, which show that even recent snow containing $2.3 \mathrm{pg} / \mathrm{g}$ is highly polluted with anthropogenic $\mathrm{Pb}$. This follows from a comparison of isotope abundances of $\mathrm{Pb}$ in surface snow and terrestrial dust extracted from ancient Antarctic ice (Dome C, depth $308 \mathrm{~m}$, approximate age 7,500 a BP), the latter being distinctly more radiogenic. This result is independent of geochemical arguments based on measurements of $\mathrm{Al}, \mathrm{Na}$ and $\mathrm{SO}_{4}$. South America is suggested as a likely source of this anthropogenic $\mathrm{Pb}$. The presence of significantly less radiogenic $\mathrm{Pb}$ in the snow adjacent to two Antarctic base stations indicates that there is contamination from station emissions, although emission from Australia is an alternative explanation for a site $33 \mathrm{~km}$ from Dumont d'Urville.
\end{abstract}

\section{Introduction}

Studies of Antarctic snow, ice and air during the 1980s showed that Antarctica is significantly polluted with anthropogenic $\mathrm{Pb}$, relative to a pristine environment, even though habitation is low and the region is isolated by the Antarctic circumpolar convergence $[\mathrm{Ng}$ and Patterson, 1981; Boutron and Patterson, 1983, 1987; Dick, 1991; Settle and Patterson, 1991; Görlach and Boutron, 1992; Suttie and Wolff, 1992]. These conclusions are based on elemental abundance patterns which showed an enrichment of $\mathrm{Pb}$ relative to its accepted natural terrestrial abundance. Mass spectrometry has played a vital role in these studies, allowing $\mathrm{pg} / \mathrm{g}$ levels of $\mathrm{Pb}$ to be accurately determined in ultraclean samples of snow and ice. However, where an element displays natural variations in isotopic composition these variations can also be used to characterise different sources of the element. Such a study was recently carried out on $\mathrm{Pb}$ in Arctic snow by Rosman et al.[1993]. The work identified the sources of $\mathrm{Pb}$ reaching central Greenland and found the relative contributions from the major sources. We have now improved the sensitivity of the technique and investigated $\mathrm{Pb}$ pollution in Antarctica, where concentrat-ions are typically a factor of ten lower than in Greenland.

\footnotetext{
'Also at UFR de Mécanique, Université Joseph Fourier de Grenoble, Domaine Universitaine, BP 68, 38401

Grenoble,France.
}

Copyright 1994 by the American Geophysical Union.

Paper number 94GL02603

0094-8534/94/94GL-02603\$03.00
Boutron and Patterson [1987] found the concentration of $\mathrm{Pb}$ in surface snow collected from Antarctica in 1983 to be $2.3 \mathrm{pg} / \mathrm{g}$, from which they estimated Antarctic air to contain $7 \mathrm{pg} / \mathrm{m}$. About $4 / 5$ of this $\mathrm{Pb}$ was estimated to have an anthropogenic origin. The study included four sites in Antarctica along a transect extending from the coast to the South Pole (Figure 1), three of which were located in Adelie Land, East Antarctica. Only the data from one site, Stake $\mathrm{D} 80$, was used to estimate air- $\mathrm{Pb}$ because the other three sites were considered to be contaminated by emissions from nearby stations at Dumont d'Urville on the coast and Amundsen-Scott at the South Pole.

\section{Observations and Discussion}

Here we present the $\mathrm{Pb}$ isotope abundances $\left({ }^{204} \mathrm{~Pb},{ }^{206} \mathrm{~Pb}\right.$, ${ }^{207} \mathrm{~Pb}$ and ${ }^{200} \mathrm{~Pb}$ ) in these same samples. We also present for comparison $\mathrm{Pb}$ isotope data for ancient Antarctic ice, obtained by analysing a section (308 $\mathrm{m}$ deep, age $\sim 7,500$ a BP) of the Dome C, $905 \mathrm{~m}$ deep, ice core. This section was decontaminated using an improved ultraclean mechanical chiselling technique derived from that developed by $\mathrm{C}$. Patterson and his coworkers [Candelone et al., 1994]. The techniques used for the isotopic analyses are refinements of those described by Rosman et al.[1993]. These measurements of isotopic abundances have for the first time allowed us to

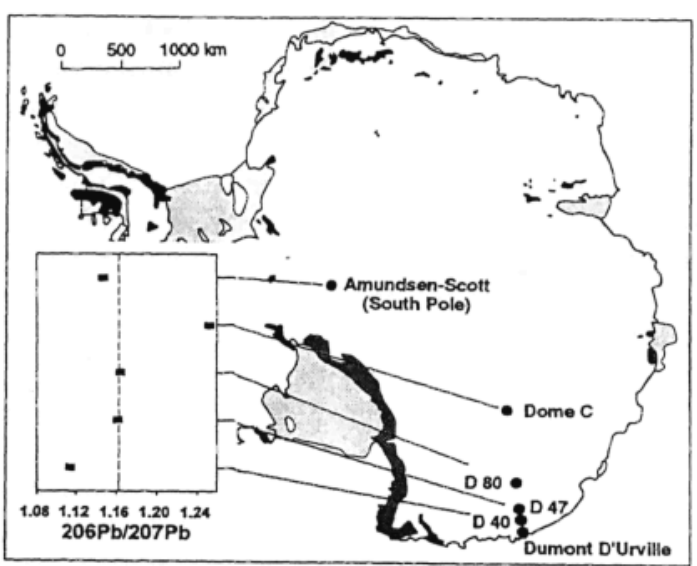

Figure 1. Sampling sites in Antarctica for the collection of the snow blocks and the Dome $\mathrm{C}$ deep ice core samples. $\mathrm{A}$ plot showing the ${ }^{206} \mathrm{~Pb} /{ }^{207} \mathrm{~Pb}$ ratio for the inner layer of the ice core and the means of the 3 inner layers for each snow-block is inset. The dotted line on the plot shows the background $\mathrm{Pb}$ component. 
Table 1. Results of Measurements and Details of Sample Collection Sites along the Dumont D'urville to D80 Trail and at the Geographic South Pole

\begin{tabular}{|c|c|c|c|c|c|c|c|}
\hline Location* & Dist.(km)** & Collection & Altitude(m) & Conc.(pg/g) $\dagger$ & $206 / 207 \#$ & $208 / 207 \#$ & $206 / 204 \#$ \\
\hline Stake D40 & 33 & $3 / 1 / 1983$ & 848 & & & & \\
\hline Layer 4 (inner) & & & & 6.6 & $1.1092(13)$ & $2.3804(27)$ & $17.167(78)$ \\
\hline Layer 3 & & & & 6.5 & $1.1248(13)$ & $2.3868(31)$ & $17.463(63)$ \\
\hline Layer 2 & & & & 6.2 & $1.1091(13)$ & $2.3792(27)$ & $17.052(78)$ \\
\hline Layer 1 & & & & 10.5 & $1.1072(44)$ & $2.3717(63)$ & $16.98(22)$ \\
\hline Stake D47 & 103 & $5 / 1 / 1983$ & 1500 & & & & \\
\hline Layer 4 (inner) & & & & 7.4 & $1.1662(15)$ & $2.4275(35)$ & $18.158(77)$ \\
\hline Layer 3 & & & & 9.9 & $1.1583(15)$ & $2.4232(24)$ & $18.031(69)$ \\
\hline Layer 2 & & & & 7.1 & $1.1592(16)$ & $2.4257(32)$ & $18.078(83)$ \\
\hline Layer 1 & & & & 24.4 & $1.1535(14)$ & $2.4196(23)$ & $17.996(44)$ \\
\hline Stake D80 & 433 & $14 / 1 / 1983$ & 2525 & & & & \\
\hline Layer 4 (inner) & & & & 2.3 & $1.1614(32)$ & $2.4291(53)$ & $18.077(80)$ \\
\hline Layer 3 & & & & 2.3 & $1.1587(29)$ & $2.4296(57)$ & $18.106(91)$ \\
\hline Layer 2 & & & & 2.8 & $1.1722(25)$ & $2.4364(27)$ & $18.290(50)$ \\
\hline Layer 1 & & & & 6.9 & $1.1520(28)$ & $2.4207(23)$ & $17.937(85)$ \\
\hline South Pole & 1274 & $18 / 1 / 1984$ & 2888 & & & & \\
\hline Layer 4 (inner) & & & & 6.3 & $1.1498(17)$ & $2.4185(21)$ & $17.838(56)$ \\
\hline Layer 3 & & & & 5.3 & $1.14753(20)$ & $2.41767(40)$ & $17.85(12)$ \\
\hline Layer 2 & & & & 5.5 & $1.1432(11)$ & $2.4147(20)$ & $17.86(13)$ \\
\hline Layer 1 & & & & 7.6 & $1.1542(23)$ & $2.4172(37)$ & $17.911(71)$ \\
\hline \multicolumn{8}{|l|}{ Dome C (depth $308 \mathrm{~m}$ ) } \\
\hline Layer 4 (innermost) & & & & $2.1 \mathrm{~s}$ & $1.2521(58)$ & $2.5072(39)$ & $19.611(96)$ \\
\hline Layer 3 & & & & $2.4 \$$ & $1.2518(45)$ & $2.5062(40)$ & $19.601(86)$ \\
\hline Perth, W.A. & & $(1982-83) \S$ & & & $1.083-1.062$ & $2.352-2.338$ & $16.76-16.42$ \\
\hline
\end{tabular}

* The decontamination procedure involved chiselling successive veneers of snow (Layers 1-4), 3-5 cm thick, from $37 \mathrm{~cm} \times 37 \mathrm{~cm} x$ $37 \mathrm{~cm}$ blocks, beginning at the surface which had been in contact with the polyethylene sampling box and working inwards (Layer 1 corresponds to the deepest horizontal layer sampled) [Boutron and Patterson, 1987].

** Distance from the coast.

$\dagger$ Isotope dilution mass spectrometry. Uncertainties $\pm 10 \%$ [Boutron and Patterson, 1987].

$\$$ Isotope dilution mass spectrometry. Uncertainties $\pm 10 \%$ [THIS WORK].

\# Isotopic ratios have been corrected for isotope fractionation (NIST SRM981) and a processing blank of $1.6 \pm 0.9 \mathrm{pg}$ (snow blocks) or

$0.75 \pm 0.9$ (Dome C). Uncertainties (shown in brackets) for the two least significant figures are $95 \%$ confidence intervals for the means

$\S$ Gasoline and acrosols [K. Rasman, unpublished data].

directly observe the influence of anthropogenic $\mathrm{Pb}$ on Antarctica independent of ambiguities associated with $\mathrm{Pb}$ concentration measurements.

The results are shown in Table 1 and Figure 1. The isotopic composition data reveal that field contamination has affected only the exposed outer layer of the snow-blocks, in agreement with the conclusions based on $\mathrm{Pb}$ concentration measurements [Boutron and Patterson, 1987]. The concentrations given in Table 1 for the snow-blocks are those reported in the earlier paper in 1987 rather than the values found during the current measurements, because we have found that samples sometimes became heterogeneous in their $\mathrm{Pb}$ concentration after freezing, storing and remelting for subsequent analysis. Only the two central layers of the Dome $\mathrm{C}$ ice core were analysed (Table 1), but since both have the same isotopic composition, they appear to be free of contamination from the penetration of surface $\mathrm{Pb}$. This conclusion is also supported by other measurements of a complete profile on an equivalent section of core not presented here.

The Dome $\mathrm{C}$ ice sample has ${ }^{206} \mathrm{~Pb} /{ }^{207} \mathrm{~Pb}=1.252$, which we attribute to terrestrial dust. We assume this dust is also present in recent snow and refer to the $\mathrm{Pb}$ derived from it as the natural component in the snow-blocks. At $2.1 \mathrm{pg} / \mathrm{g}$ the $\mathrm{Pb}$ concentration of the interglacial snow is substantially lower than for the Last Glacial Maximum (LGM, $29.3 \mathrm{pg} / \mathrm{g}$ : Boutron and Patterson, 1986), but this may still be enhanced due to the storage problems already described. All four snow-blocks have considerably lower ${ }^{206} \mathrm{~Pb} /{ }^{207} \mathrm{~Pb}$ than this ancient dust, providing indisputable evidence that all four must contain a significant proportion of anthropogenic $\mathrm{Pb}$. The association of anthropogenic $\mathrm{Pb}$ with lower ${ }^{26} \mathrm{~Pb} / \mathrm{Pb}$ is discussed in the following sections.

We have estimated the anthropogenic contributions to the snow at each sampling site, based on available information on the potential sources of $\mathrm{Pb}$. Although this information tends to be rather limited, the analysis serves to illustrate the value of measuring $\mathrm{Pb}$ isotope ratios.

Boutron and Patterson [1987] attributed the higher $\mathrm{Pb}$ concentrations at D40 and D47, $33 \mathrm{~km}$ and $103 \mathrm{~km}$ respectively from the coast, to emissions from the coastal station of Dumont d'Urville, although Suttie and Wolff [1993] claim that significant fallout upwind at these distances is unlikely. Our measurements show that $\mathrm{D} 40$ has ${ }^{206} \mathrm{~Pb} /{ }^{207} \mathrm{~Pb}$ $=1.1092$ compared to 1.1662 at D47, which suggests that only D40 was significantly affected by station emissions. Since 1970 this base has purchased gasoline in Australia from either Shell or BP Australia. Perth gasoline supplied by BP (British Petroleum) had a ${ }^{206} \mathrm{~Pb} /{ }^{207} \mathrm{~Pb}$ of $1.083-1.062$ between 1982 and 1983 (Table 1) which can account for a lowering of the $\mathrm{Pb}$ isotopic ratio in the snow.

Another possible explanation for the lower isotopic ratios at D40 is a direct contribution from Australian emissions. Atmos-pheric general circulation models show that Australia is a principle source of the dust reaching East Antarctica [Joussaume, 1993], although the same models fail to reproduce the high dust levels of the LGM found in the Dome $\mathrm{C}$ ice core. 
The high $\mathrm{Pb}$ concentration at $\mathrm{D} 47(7.4 \mathrm{pg} / \mathrm{g})$ compared to D80 (2.3 pg/g) led Boutron and Patterson [1987] to conclude that $D 47,70 \mathrm{~km}$ further inland from D40, was also influenced by Dumont d'Urville emissions. However, the similarity in the average isotopic composition of the $\mathrm{Pb}$ (1.161 for D47 versus 1.164 for D80) discounts this possibility and, further, points to a common source for the $\mathrm{Pb}$. In addition, since the two blocks were collected 10 days apart in 1983 and the precipitation rates were similar over the 6 month integration period $\left(26 \mathrm{~g} \mathrm{H}_{2} \mathrm{O} \mathrm{cm}_{-2}^{-2} \mathrm{yr}^{-1}\right.$ at $\mathrm{D} 47$ and 24

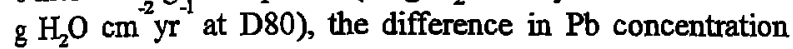
suggests a large spatial variation in the $\mathrm{Pb}$ flux. Suttie and Wolff [1992] have suggested that this may be due to seasonal variations, but this seems unlikely because the period of accumulation was essentially the same.

The $\mathrm{Pb}$ in $\mathrm{D} 47$ and $\mathrm{D} 80$ snow $\left({ }^{206} \mathrm{~Pb} /{ }^{207} \mathrm{~Pb}=1.163\right.$, mean of 3 inner layers) will be referred to as background $\mathrm{Pb}$. Assuming this to be present throughout East Antarctica and at the Pole, it is possible to construct a simple linear mixing model based on isotopic ratios that allows $\mathrm{Pb}$ contributions to the snow from base station emissions to be calculated.

In the case of $\mathrm{D} 40$, two sources of $\mathrm{Pb}$ which could lower the isotopic ratio from 1.163 to 1.114 (mean of 3 inner layers) will be considered. The first is leaded gasoline emissions from Dumont d'Urville. A $54 \%$ (3.5 pg/g) contribution of $\mathrm{Pb}$ with ratio 1.072 will achieve this result. Lead emissions from Australia are another possibility. An estimate of the isotopic composition of Australian emissions, based on imports of alkyl $\mathrm{Pb}$ from the United Kingdom and the United States between 1982 and 1985, yields $\sim 1.09$, assuming ${ }^{206} \mathrm{~Pb} /{ }^{207} \mathrm{~Pb}$ ratios of 1.07 and 1.19 respectively for the two suppliers. To lower the ratio at D40 with this $\mathrm{Pb}$ would require a $67 \%$ contribution to the snow.

Lead in the Pole sample has $\mathrm{a}{ }^{206} \mathrm{~Pb} /{ }^{207} \mathrm{~Pb}=1.147$ (mean of 3 inner layers), which is lower than D47 and D80, indicating that it was contaminated by emissions from Amundsen-Scott base located only $7.3 \mathrm{~km}$ away. In this case the origin of the gasoline is less certain. In 1984, gasoline was purchased in Greece. If we assume that same occurred in 1982 and 1983 then the ${ }^{206} \mathrm{~Pb} /{ }^{207} \mathrm{~Pb} \approx 1.14$ [Rosman et al., 1994]. About $70 \%$ of the $\mathrm{Pb}$ in the snow can then be attributed to emissions from the base.

Because the ${ }^{206} \mathrm{~Pb} /{ }^{207} \mathrm{~Pb}$ ratios in all snow-blocks are significantly lower than in Dome $\mathrm{C}$ ice, it is clear that the $\mathrm{Pb}$ in all samples, even D47 and D80, is a mixture of natural and anthropogenic $\mathrm{Pb}$. However, because the isotopic composition of the anthropogenic component of the D47 and $\mathrm{D} 80 \mathrm{~Pb}$ is not precisely known, the anthropogenic proportion cannot be computed uniquely. However, the measured isotopic ratios do impose limits on the size of the anthropogenic component. The lowest acceptable ${ }^{206} \mathrm{~Pb} /{ }^{207} \mathrm{~Pb}$ for anthropogenic $\mathrm{Pb}$ is 1.07 , which yields an anthropogenic contribution of $49 \%$. Hence, more than $49 \%$ of the background $\mathrm{Pb}$ must have an anthropogenic origin.

Because all three isotopic ratios shown in Table 1 are highly correlated, the same conclusions will be reached regardless of which pair of isotopes are chosen. However, because the ${ }^{206} \mathrm{~Pb} /{ }_{208}^{207} \mathrm{~Pb}$ displays relatively large changes in comparison with ${ }_{206}^{208} \mathrm{~Pb} /{ }^{207} \mathrm{~Pb}$ and can be measured more precisely than ${ }^{206} \mathrm{~Pb} /{ }^{204} \mathrm{~Pb}$ in small samples, it has been used for the above calculations.

Further information can be extracted from the isotopic data if reliable geochemical data are available. Boutron and

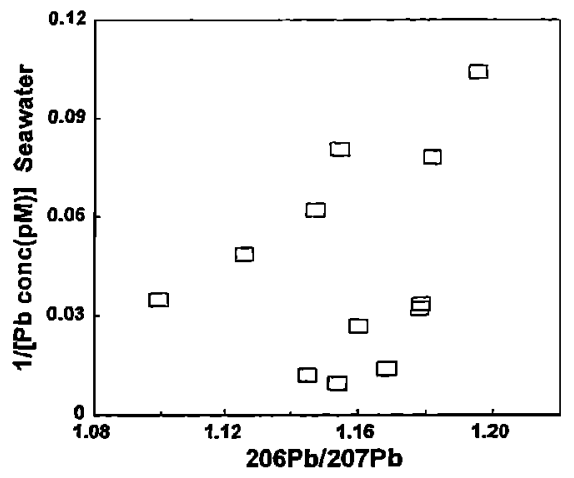

Figure 2. The inverse of the $\mathrm{Pb}$ concentration versus the ${ }^{206} \mathrm{~Pb}{ }^{207} \mathrm{~Pb}$ ratio for Antarctic seawater, measured by Flegal et al.[1993]. A component characterised by ${ }^{206} \mathrm{~Pb} /{ }^{207} \mathrm{~Pb} \approx 1.16$ can be easily identified.

Patterson [1987] claimed that $80 \%$ of the $\mathrm{Pb}$ in $\mathrm{D} 80$ was anthropogenic, based on geochemical arguments. This value, taken together with the isotopic composition of the inner layer of the Dome C sample (ratios: $1.2521,2.5072,19.611$ ) and an average for the three inner layers of D47 and D80 (ratios: $1.1627,2.4286,18.124$ ), yields isotopic ratios of ${ }^{206} \mathrm{~Pb} /{ }^{207} \mathrm{~Pb}=1.140,{ }^{208} \mathrm{~Pb} /{ }^{207} \mathrm{~Pb}=2.409$ and ${ }^{206} \mathrm{~Pb} /{ }^{204} \mathrm{~Pb}=$ 17.75 for the anthropogenic component of the background $\mathrm{Pb}$. This composition is similar to that of European gasoline.

The Antarctic snow analysed contains four distinct $\mathrm{Pb}$ components characterised by ${ }^{206} \mathrm{~Pb} /{ }^{207} \mathrm{~Pb}$ ratios of 1.252 (natural $\mathrm{Pb}$, Dome C), 1.072 (gasoline, Dumont d'Urville), 1.140 (gasoline, Amundsen-Scott) and 1.163 (background $\mathrm{Pb}$, East Antarctica). Flegal et al.[1993] measured $\mathrm{Pb}$ isotopes in seawater collected in the south Atlantic Ocean and between South America and the Antarctic Peninsula. There is evidence in their data of a component with a ratio of -1.16 . This is most easily recognised on a plot of the inverse of the $\mathrm{Pb}$ concentration versus ${ }^{206} \mathrm{~Pb} /{ }^{207} \mathrm{~Pb}$ as shown in Figure 2. Any mixture of two components will fall on a straight line joining them, while a mixture of three components will fall inside a triangle. Figure 2 suggests that there are at least three different components in the seawater, one with a ratio of $\sim 1.16$ was not previously recognised. This may be the background $\mathrm{Pb}$ we find in Antarctic snow. The two other components were identified by Flegal et al.[1993] as Pb from the combustion of gasoline in the Southern Hemisphere and from volcanic emissions, aeolian dust, and ice-rafted sediment.

Because of the paucity of $\mathrm{Pb}$ isotope data for the Southern Hemisphere it is not possible to identify the origin of the background $\mathrm{Pb}$ with certainty. Grousset et al.[1992] identified Patagonia in Argentina as the source of the dust reaching Antarctica during the LGM based on measurements of $\mathrm{Sr}$ and $\mathrm{Nd}$ isotope ratios, and rare earth element abundances in Dome $\mathrm{C}$ ice. A reexamination of $\mathrm{Na}, \mathrm{Al}$ and Ca concentration data for deep Antarctic ice cores by Delmas and Petit [1994] has also identified South America as the source of Antarctic aerosols. If this transport mechanism persists today then emissions from cities in southern South America such as Buenos Aires, Rio de Janeiro or Santiago could contribute to the anthropogenic component of the background $\mathrm{Pb}$. No relevant isotopic data are available to test this hypothesis, and no $\mathrm{Pb}$ isotope ratios for South American 


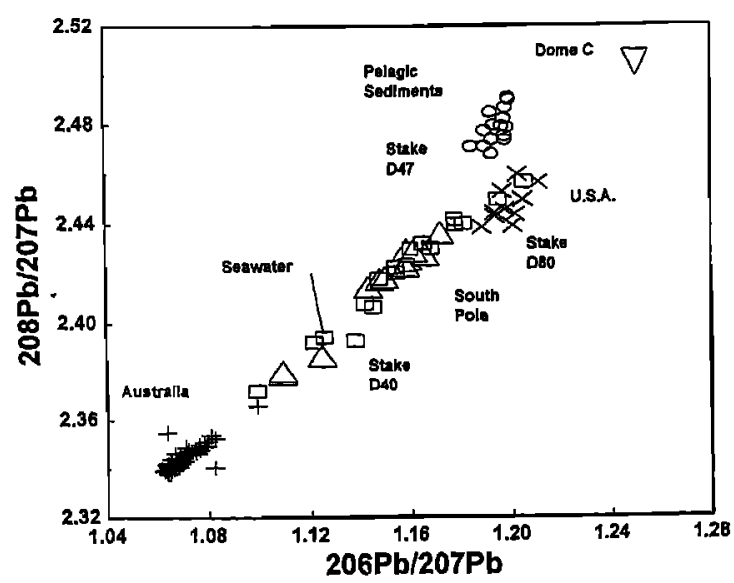

Figure 3. The plot shows isotope ratios of $\mathrm{Pb}$ in Antarctic snow (triangle) [THIS WORK], Dome $\mathrm{C}$ dust (inverted triangle) [THIS WORK], Antarctic seawater (square) [Flegal et al., 1993], pelagic sediments adjacent to South America (ellipse) [Chow and Patterson, 1962], and gasoline and aerosols from Perth, Australia, during 1982-83 (plus) [K. Rosman, unpublished data] and from the United States during 1971-74 (cross) [Rabinowitz and Wetherill, 1972; Chow et al., 1975].

gasoline have been reported since 1969 [Chow et al., 1975], but this remains a likely source region.

The relationship between the isotopic composition of Antarctic snow, Dome C dust, pelagic sediments (aeolian origin, located near southern South America), gasoline and seawater is shown in Figure 3. On such a diagram, involving only isotopic ratios, binary mixtures will lie on straight lines. We see that Australian gasoline, seawater, snow-blocks and Dome $\mathrm{C}$ ice lie on a common line, while US gasoline $\mathrm{Pb}$ and South American pelagic sediments lie in separate fields [Chow and Patterson, 1962; Rabinowitz and Wetherill, 1972; Chow et al., 1975]. The overlap of the seawater and snowblocks data may indicate a similar origin for the $\mathrm{Pb}$. However, on such a diagram a unique signature for background $\mathrm{Pb}$ cannot be readily identified.

\section{Conclusion}

Highly sensitive mass spectrometric techniques have been developed to measure the abundance of $\mathrm{Pb}$ isotopes in snow and ice containing a few $\mathrm{pg} / \mathrm{g}$. A comparison of $\mathrm{Pb}$ isotope abundances in surface snow collected at remote locations in Antarctica with ancient ice shows unequivocally that present day snow, and by implication the Antarctic air, is highly polluted with anthropogenic $\mathrm{Pb}$. Isotopic systematics indicates that $\mathrm{Pb}$ from two distinct sources is found at remote Antarctic localities; a natural component associated with aeolian dust, possibly originating from South America, and an anthropogenic component possibly from the same region. Evidence of $\mathrm{Pb}$ contamination from base station emissions was also detected adjacent Dumont d'Urville and AmundsenScott. An alternative explanation for the contamination at $\mathrm{D} 40,33 \mathrm{~km}$ from Dumont d'Urville, is atmospheric transport from Australia.

Acknowledgments. This project was supported by the Australian Research Council, the Ministere de l'Environment (grants 8904 and 92205), the Institut National des Sciences de I'Univers., the University of Grenoble, and the U.S. National
Science Foundation (grant DPP 840-3090). Helpful comments on the paper were provided J. de Laeter, R. Loss, I. Fletcher, R. Delmas and two anonymous reviewers.

\section{References}

Boutron, C.F. and C.C. Patterson, The occurrence of $\mathrm{Pb}$ in Antarctic recent snow, fim deposited over the last two centuries and prehistoric ice, Geochim. Cosmochim. Acta, 47, 1355-1368, 1983.

Boutron C.F. and C.C. Patterson, Relative levels of natural and anthropogenic $\mathrm{Pb}$ in recent Antarctic snow, J. Geophys. Res, 92, 8454-8464, 1987.

Candelone J.-P., S. Hong and C.F. Boutron, An improved method for decontaminating polar snow or ice cores for heavy metals analysis, Anal. Chim Acta, in press.

Chow, T.J. and C.C. Patterson, The occurrence and significance of $\mathrm{Pb}$ isotopes in pelagic sediments, Geochim Cosmochim. Acta, 26, 263-308, 1962.

Chow, T.J., C.B. Snyder and J.L. Earl, Isotope ratios of $\mathrm{Pb}$ as pollutant source indicators. United Nations FAO and International Atomic Energy Association Symposium, Vienna, Austria. (IAEA-SM-191/4) Proceedings, pp. 95-108, 1975.

Delmas, R.J. and J.R. Petit, Present Antarctic aerosol composition: a memory of ice age atmospheric dust? Geophys. Res. Lett, 21, 879-882, 1994.

Dick, A.L., Concentrations and sources of metals in the Antarctic Peninsula aerosol, Geochim Cosmochim Acta, 55, 1827-1836, 1991.

Flegal, A.R., H. Maring and S. Niemeyer, Anthropogenic $\mathrm{Pb}$ in Antarctic sea water, Nature, 365, 242-244, 1993.

Gorlach U. and C.F. Boutron, Variations in heavy metals concentrations in Antarctic snows from 1940 to 1980 , J. Amos. Chem, 14, 205-222, 1992.

Grousset, F.E., P.E. Biscaye, M. Revel, R-J. Petit, K. Pye, S. Joussaume and J. Jousel, Antarctic (Dome C) ice-core dust at 18 k.y. B.P.: Isotopic constraints on origins, Earth Planet. Sci. Letters, 111, 175-182, 1992.

Joussaume, S., Paleoclimatic tracers: an investigation using an atmospheric general circulation model under ice age conditions 1. desert dust. J. Geophys. Res, 98, 2767-2805, 1993.

$\mathrm{Ng}$, A. and C.C. Patterson, Natural concentrations of $\mathrm{Pb}$ in ancient Arctic and Antarctic ice, Geochim. Cosmochim Acta, 45, 2109-2121, 1981.

Rabinowit, M.B. and G.W. Wetherill, Identifying sources of $\mathrm{Pb}$ contamination by stable isotope techniques, Envir. Sci. \& Technol., 6, 705-709, 1972.

Rosman, K.J.R., W. Chisholm, C.F. Boutron, J.-P. Candelone and $\mathrm{S}$. Hong, Isotopic evidence for the source of $\mathrm{Pb}$ in Greenland snows since the late 1960s, Nature, 362, 333-334, 1993.

Rosman, K.J.R., W. Chisholm, C.F. Boutron, J.-P. Candelone and U. Görlach, Isotopic evidence to account for changes in the concentration of $\mathrm{Pb}$ in Greenland between 1960 and 1988, Geochim. et Cosmochim. Acta, 58, 3265-3269.

Settle, D.M. and C.C. Patterson, Eolian inputs of $\mathrm{Pb}$ to the South Pacific via rain and dry deposition from industrial and natural sources, Geochim Cosmochim. Acta, Spec. Pub. No.3, Eds H.P. Taylor, J.R. ONeil and I.R. Kaplan, 1991.

Suttie, E.D. and E.W. Wolff, Seasonal input of heavy metals to Antarctic snow, Tellus, 44B, 351-357, 1992.

Suttie, E.D. and E.W. Wolff, The local deposition of heavy metal emissions from point sources in Antarctica, Atmos Environ., 27A, 1833-1841, 1993.

K.J.R. Rosman and W. Chisholm, Department of Applied Physics, Curtin University of Technology, Bentley 6102, W.A., Australia. (e-mail: trosmankj@cc.curtin.edu.au)

(Received April 19, 1994; revised July 26, 1994; accepted September 7, 1994) 